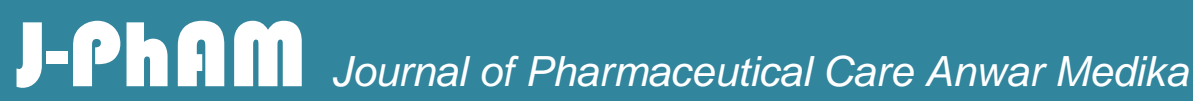

Artikel Penelitian

\section{Uji Aktivitas Fibrinolisis Ekstrak Alkaloid Total Rimpang Lengkuas Merah (Alpinia Purpurata (Vielli) K.Schum) Secara In Vitro}

\author{
Martina Kurnia Rohmah ${ }^{1}$, Djelang Zainuddin Fickri ${ }^{1}$, Wahyu Kasifa ${ }^{1}$, Khurin In Wahyuni ${ }^{1}$ \\ STIKES RS Anwar Medika \\ Email: martina.kurniarohmah@gmail.com
}

\begin{abstract}
Abstrak: Ketidakseimbangan hemostasis akan meningkatan agregasi trombosit, hiperkoagulasi, dan penurunan aktivitas fibrinolisis yang menyebabkan terbentuknya sumbatan (trombus) pada pembuluh darah. Adanya gangguan tersebut menyebabkan akan menimbulkan sejumlah penyakit seperti Ateroskelrosis, Infark miokard, Iskemia, Stroke dan Diabetes Tipe II. Terapi yang selama ini digunakan diantaranya Streptokinase dan Nattokinase yang memiliki efek samping berupa Perdarahan, sehingga diperlukan penelitian untuk mencari agen fibrinolisis dari bahan alam. Alkaloid merupakan salah satu senyawa yang memiliki aktivitas sebagai fibrinolisis yang menghambat TNF- $\alpha$ agar tidak terjadi sekresi PAI-1 yang menghambat plasminogen sehingga menjadi plasmin yang dapat mendegradasi fibrin. Salah satu tanaman yang memiliki kandungan senyawa alkaloid yaitu rimpang lengkuas merah (Alpinia purpurata (Velli) K.Schum). Penelitian ini bertujuan untuk mengetahui perbedaan dan pengaruh persen fibrinolisis pada pemberian ekstrak alkaloid total Rimpang Lengkuas Merah pada konsentrasi $0,1 \mathrm{mg} / \mathrm{ml}, 0,5 \mathrm{mg} / \mathrm{ml}, 1$ $\mathrm{mg} / \mathrm{ml}$. jenis penelitian ini menggunakan experimental control study dengan rancangan acak lengkap (RAL) pada 25 subjek secara in vitro. Penelitian ini terbagi menjadi tiga tahap. Tahap pertama ekstraksi dan pemisahan alkaloid total Rimpang Lengkuas Merah didapatkan sebanyak 4,2\%. Tahap kedua uji fitokimia dengan parameter yang diuji alkaloid positif dan sedangkan flavonoid, tannin dan saponin negatif. Tahap ketiga pengujian aktivitas fibrinolisis dengan banyaknya persen lisis bekuan (fibrinolisis). Hasil penelitian menunjukkan bahwa terdapat perbedaan yang signifikan $(\mathrm{p}=0,017<0,05)$ antar kelompok kontrol (Kontrol positif dan negatif) dengan kelompok perlakuan (Alkaloid total ekstrak Rimpang Lengkuas Merah konsentrasi $0,1 \mathrm{mg} / \mathrm{ml}, 0,5 \mathrm{mg} / \mathrm{ml}$ dan 1 $\mathrm{mg} / \mathrm{ml}$ ). Pemberian alkaloid total ekstrak Rimpang Lengkuas Merah memiliki pengaruh (Fhitung $=5,180>$ Ftabel) dan terdapat hubungan cukup kuat $(\mathrm{r}=0,473)$ antar konsentrasi perlakuan terhadap persen fibrinolisis. Aktivitas fibrinolisis yang maksimal terjadi pada konsentrasi $1 \mathrm{mg} / \mathrm{ml}$ ekstrak alkaloid total Rimpang lengkuas merah.
\end{abstract}

Kata kunci : Trombus, Alkaloid, Fibrinolisis 


\section{J-PhAMII Jounal of P harmecoutical Care Amwer Mootha}

Artikel Penelitian

Abstract: Hemostasis imbalance will increase platelet aggregation, hypercoagulation, and decreased fibrinolysis activity which causes the formation of blockages (thrombus) in blood vessels. This disorder will cause diseases such as atherosclerosis, myocardial infarction, ischemia, stroke and type II diabetes. The therapies that have been used include Streptokinase and Nattokinase which have side effects such as bleeding, so this research is needed to look for fibrinolysis agents from natural ingredients. Alkaloid is one of the compounds that have activity as fibrinolysis that inhibits TNF- $\alpha$ to prevent PAI1 secretion from inhibiting plasminogen so that it becomes plasmin that can degrade fibrin. Plants that contains alkaloid compounds is the red galangal rhizome (Alpinia purpurata (Velli) K.Schum). The purpose of this study to determine the differences and the effect of percent fibrinolysis on the total alkaloid extract of Red Galangal Rhizome administration at a concentration of $0.1 \mathrm{mg} / \mathrm{ml}, 0.5 \mathrm{mg} / \mathrm{ml}$, and $1 \mathrm{mg} / \mathrm{ml}$. This research uses an experimental control study with a completely randomized design in 25 subjects in vitro. This research is divided into three stages. The first was extraction and separation of total alkaloid Red Galangal Rhizome as much as 4.2\%. The second stage of phytochemical testing with parameters tested alkaloid positif and another such as flavonoid, tannin and saponin are negatif. The third stage is testing the activity of fibrinolysis with percentage of clot lysis (fibrinolysis). The results showed that there were significant differences $(p=0.017<0.05)$ between the control group (positive and negative controls) with the treatment group (total Alkaloid extract of Red Galangal Red Rhizome concentration $0.1 \mathrm{mg} / \mathrm{ml}, 0.5$ $\mathrm{mg} / \mathrm{ml}$ and $1 \mathrm{mg} / \mathrm{ml}$ ). The administration of total alkaloid extract of Red Galangal Rhizome has an influence $(F=5.180>$ Ftable $)$ and there is a strong relationship ( $r=0.473$ ) between the concentration of the treatment of percent fibrinolysis. Maximum fibrinolysis activity occurs at a concentration of $1 \mathrm{mg} /$ $m l$.

\section{Artikel Penelitian}

Keywords: Thrombus, Alkaloids, Fibrinolysis

\section{PENDAHULUAN}

Hemostasis merupakan fungsi tubuh yang dapat mempertahankan keenceran darah sehingga darah tetap mengalir dalam pembuluh darah. Proses hemostasis memiliki peranan penting pada keadaan normal yang meliputi proses agregasi platelet, koagulasi dan fibrinolisis. Hemostasis terdiri dari hemostasis primer dan hemostasis sekunder. Hemostasis primer yang terdiri dari proses agregasi platelet dan koagulasi menyebabkan darah akan membeku. Jika proses pembekuan darah telah selesai, maka hemostasis primer 


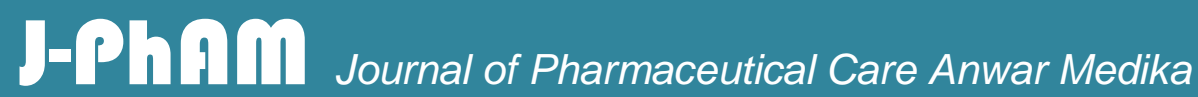

\section{Artikel Penelitian}

akan diseimbangkan dengan hemostasis sekunder berupa proses fibrinolysis yang akanMmelisiskan bekuan darah sehingga darah tetap encer (Arbind, 2011). Pada kasus tertentu seperti Diabetes Mellitus Tipe II, glukosa darah yang tinggi menyebabkan peningkatan agregasi platelet (hiperagregasi). Pasien DM Tipe II juga memiliki kecenderungan pada penurunan waktu pembekuan darah (Borisoff, 2011). Pasien dengan DM Tipe II juga mengalami gangguan pembentukan plasmin dan rusaknya struktur bekuan darah yang mengakibatkan permeabilitas darah berkurang, akibatnya plasmin tidak dapat masuk ke dalam bekuan untuk melisiskan bekuan tersebut. Terganggunya sistem hemostasis pada DM Tipe II ini menyebabkan darah cenderung membeku dan membentuk sumbatan (Rayfield, 2002).

Adanya efek samping dari berbagai obat fibrinolisis di atas, maka diperlukan pengembangan obat salah satunya adalah berbasis bahan alam. Salah satu jenis senyawa dari bahan alam yang diketahui memiliki aktivitas antiplatelet, antikoagulan dan fibrinolisis adalah alkaloid. Berbagai jenis alkaloid telah terbukti memiliki aktivitas fibrinolisis dengan menghambat TNF- $\alpha$ agar tidak terjadi sekresi PAI-1 sehingga plasmin menjadi aktif dan fibrin dapat lisis (Ku et al., 2013) (Lee et al., 2016).

Rimpang lengkuas merah (Alpinia purpurata (Vielli) K.Schum) merupakan salah satu tanaman dalam family Zingiberaceae yang memiliki kandungan senyawa alkaloid, flavonoid, terpenoid, dan steroid (Manohara et al., 2004). Rimpang lengkuas merah memiliki sejumlah aktivitas farmakologis di antaranya sebagai menetralkan racun (antioksidan), menurunkan panas (antipiuretik), menghilangkan rasa sakit (analgesik), meluruhkan kentut (carminative), meluruhkan kecing (diuretik), obat jamur, menyegarkan (stimulant), memperkuat lambung dan meningkatkan nafsu makan (stomachica) (Hariana, 2008). Sejauh ini penelitian tentang efek fibrinolisis dari alkaloid rimpang lengkuas merah masih belum dilakukan. Untuk itu perlu dilakukan penelitian tentang uji aktivitas fibrinolisis pada alkaloid total rimpang lengkuas merah.

Uji aktivitas fibrinolisis dilakukan dengan cara mengamati persen fibrinolisis berdasarkan nilai waktu lisis bekuan atau waktu Clot Lysis (CL). CL adalah merupakan parameter untuk mengetahui kemampuan fibrinolisis dengan berprinsip pada banyak 


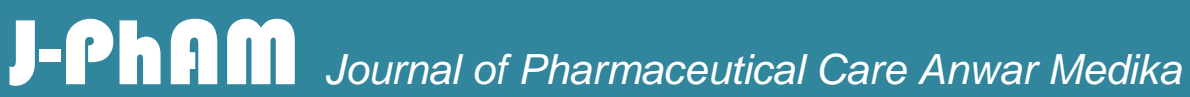

Artikel Penelitian

sedikitnya retraksi bekuan darah selama masa inkubasi. Persentase (\%) fibrinolisis yaitu kemampuan suatu zat untuk dapat melisiskan bekuan. Dengan mengetahui persen lisis bekuan, maka kita dapat mengetahui aktivitas alkaloid total rimpang lengkuas merah.

\section{BAHAN DAN METODE PENELITIAN}

\section{Waktu dan Tempat Penelitian}

Penelitian ini dilaksanakan di laboratorium Teknologi Farmasi STIKES Rumah Sakit Anwar Medika yang terletak di Jl. Raya By Pass Krian KM 33 Sidoarjo. Penelitian ini dilaksanakan pada bulan Maret - Juni 2019.

\section{Alat dan Bahan Penelitian}

Bahan yang digunakan adalah serbuk Rimpang Lengkuas Merah (Alpinia purpurata (Velili) K. schum) yang didapat dari Materia Medika Batu Malang, Etanol 96\%, HCL 2M, NH4OH, Asam Sulfat, Kloroform, HCL 2N, Etil Asetat (CH3CO2CH2CH3), dan Aquades.

Sedangkan alat yang digunakan adalah Labu Ukur, Corong Pisah, Gelas Ukur, Beaker Gelas, Pipet Volume, Pipet Mikro, plat tetes, Gelas arloji, Pipet tetes, corong, Tabung reaksi, Batang pengaduk.

\section{Cara Pembuatan}

\section{Pembuatan Serbuk Simplisia Rimpang Lengkuas Merah}

Sampel penelitian berupa rimpang Lengkuas Merah (Alpinia purpurata (Vielli) K.Schum) yang diperoleh dari Balai Penelitian Tanaman Obat (BPTO) Materia medika, Jawa Timur. Rimpang Lengkuas Merah dibersihkan dan dicuci terlebih dahulu. Setelah pencucian, kemudian dikeringkan dengan diangin-anginkan. Sampel yang sudah kering dihaluskan menjadi serbuk serbuk Rimpang Lengkuas Merah.

\section{Ekstraksi Lengkuas Merah}

Sebanyak 750 gram serbuk rimpang lengkuas merah dimaserasi 2-3 kali menggunakan pelarut etanol $96 \%$ etanol yang diperoleh kemudian dipekatkan dengan Rotary Evaporatory hingga diperoleh Ekstrak etanol Rimpang Lengkuas Merah. 
Artikel Penelitian

\section{Pembuatan Pereaksi untuk Skrining Fitokimia}

\section{a. Pereaksi Mayer}

Sebanyak 136 mg $\mathrm{HgCl} 2$ dilarutkan dalam 6 mL aquades. Pada bagian yang lain larutkan pula 500 mg KI dalam $1 \mathrm{~mL}$ aquades. Kedua larutan ini kemudian dicampur dan diencerkan dengan aquades sampai $10 \mathrm{~mL}$. Reagen ini harus disimpan dalam botol yang berwarna coklat, agar tidak terjadi kontak langsung dengan cahaya.

\section{b. Pereaksi Dragendorff}

Sebanyak $800 \mathrm{mg}$ KI dilarutkan dalam $25 \mathrm{~mL}$ aquades, edangkan pada bagian yang lain dilarutkan $85 \mathrm{mg}$ bismut subnitrat dalam $1 \mathrm{~mL}$ asam asetat glasial dan $4 \mathrm{~mL}$ aquades. Kedua larutan ini kemudian dicampurkan. Larutan disimpan dalam botol berwarna coklat. Dalam penggunaannya, larutan ini diencerkan dengan 2/3 bagian larutan $2 \mathrm{~mL}$ asam asetat glasial dalam $10 \mathrm{~mL}$ aquades.

\section{c. Pereaksi Wagner}

Sebanyak 127 mg I2 dan 2 g KI dilarutkan dalam $1 \mathrm{~mL}$ aquades. Larutan ini kemudian diencerkan dengan aquades hingga $10 \mathrm{~mL}$. Endapan yang terbentuk disaring dan disimpan dalam botol berwarna coklat.

\section{Alkaloid Total Rimpang Lengkuas Merah}

Ditimbang 10 gram ekstrak etanol lalu dilarutkan dalam $100 \mathrm{ml}$ etil asetat kemudian disaring. Residu di siapkan untuk alkaloid total. Residu dilarutkan dengan $100 \mathrm{ml}$ etanol dan ditambahkan HCL 2N sampai pH 2, kemudian dipartisi dengan $100 \mathrm{ml}$ kloroform, dan $30 \mathrm{ml}$ aquades lapisan kloroform lalu dipisahkan. Lapisan etanol ditambahkan dengan $\mathrm{NH} 4 \mathrm{OH} 1 \mathrm{~N}$ hingga $\mathrm{pH} 12$ kemudian dipartisi lagi dengan $100 \mathrm{ml}$ kloroform diuapkan sehingga diperoleh ekstrak kloroform (alkaloid total) lalu dikeringkan. Total alkaloid di uji fitokimia untuk memastikan adanya alkaloid (Ginting et al., 2013).

\section{Uji Fitokimia Alkaloid}

Beberapa $\mathrm{mL}$ ekstrak etanol rimpang lengkuas merah ditambahkan dengan 2 mL kloroform Filtrat kemudian ditambahkan 3-5 tetes $\mathrm{H} 2 \mathrm{SO} 4$ pekat lalu dikocok hingga terbentuk dua lapisan. 


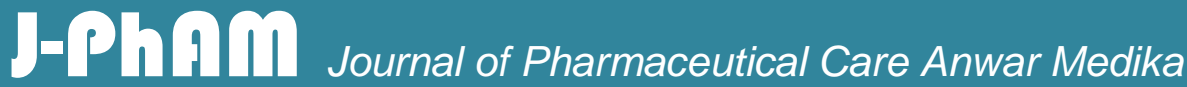

Artikel Penelitian

Lapisan atas dipindahkan ke dalam tiga tabung reaksi masing-masing 2,5 ml. Ketiga larutan ini dianalisis dengan pereaksi Mayer, Dragendorff dan Wagner sebanyak 4-5 tetes. Terbentuknya endapan menunjukkan bahwa sampel tersebut mengandung alkaloid. Reaksi dengan pereaksi Mayer akan terbentuk endapan putih, dengan pereaksi Dragendorff terbentuk endapan merah jingga dan dengan pereaksi wagner terbentuk endapan coklat (Harborne, 1987).

\section{Penetapan Kadar Alkaloid Total}

Penetapan kadar total alkaloid menggunakan metode Harbone (1987). Ekstrak etanol dikeringkan dengan natrium sulfat anhidrat kemudian dipekatkan dan setelah itu ekstrak ditimbang bobotnya (Y). Ekstrak air - basa diuapkan lalu diekstraksi dengan etanol dan diupkan kembali. Setelah itu dipekatkan dan ditimbang (z). Jumlah alkaloid total yang terkandung didalam rimpang lengkuas merah adalah:

Kadar total Alkaloid $(\%)=\underline{X+Z} \times ! 00 \%$

\section{$\mathrm{Z}$}

Keterangan :

$\mathrm{X} \quad$ : Bobot simplisia yang diekstraksi

Y : Bobot kloroform: etanol

$\mathrm{Z} \quad$ : Bobot air: basa

\section{Preparasi Perlakuan}

\section{a. Pembuatan Kontrol Negatif}

Kontrol negatif yang digunakan untuk fibrinolisis adalah etanol.

\section{b. Pembuatan Kontrol Positif}

Kontrol positif yang digunakan untuk fibrinolisis adalah Nattokinase-10 sediaan kaplet (@ 100 mg Nattokinase). Diambil 1 kapsul Nattokinase-10 (100 mg Nattokinase) digerus dan dimasukkan ke dalam labu ukur 10 ml, kemudian ditambahkan larutan tween $801 \%$ sebanyak $5 \mathrm{ml}$, ditambah 28 aquades hingga $10 \mathrm{ml}$, suspensi dikocok hingga terdispersi merata sehingga dapat suspense Nattokinase $10.000 \mu \mathrm{g} / \mathrm{ml}$ (10 $\mathrm{mg} / \mathrm{ml})$. 


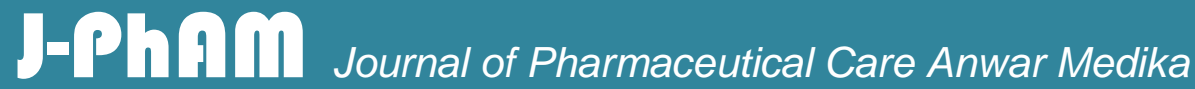

\section{Artikel Penelitian}

\section{c. Pembuatan Sampel Alkaloid Total Rimpang Lengkuas Merah}

Sampel Alkaloid total yang digunakan antara lain $0,1 \mathrm{mg} / \mathrm{ml}, 0,5 \mathrm{mg} / \mathrm{ml}, 1 \mathrm{mg} / \mathrm{ml}$. Pembuatan variasi larutan total alkaloid dibuat dengan terlebih dahulu dengan cara menimbang serbuk ekstrak alkaloid sebanyak $10 \mathrm{mg}$ dan ditambahkan pelarut etanol 96\% sebanyak $10 \mathrm{~mL}$. Selanjutnya pembuatan larutan konsentrasi 0,5 mg/mL diambil sebanyak $5 \mathrm{~mL}$ dan di tambah $10 \mathrm{~mL}$ etanol, pembuatan konsentrasi alkaloid total 0,1 $\mathrm{mg} / \mathrm{mL}$ diambil dari konsentrasi $0,5 \mathrm{mg} / \mathrm{mL}$ ditambahkan etanol sebanyak $10 \mathrm{~mL}$.

\section{d. Preparasi Sampel Uji Darah}

Preparasi sampel Whole blood diambil dari vena sampel banyak $5 \mathrm{ml}$ menggunakan spuit steril ukuran 22, tourniquet. Darah vena yang sudah diambil dimasukkan ke dalam tabung non- EDTA sesuai dengan kebutuhan Sampel darah diperoleh dari 5 orang wanita dengan berat badan tidak lebih dari $70 \mathrm{~kg}$, usia berkisar 20-25 tahun, keadaan fisik yang sehat dan tidak memiliki riwayat penyakit perdarahan yang berkepanjangan.

\section{Perlakuan dan Uji Aktivitas Agen Fibrinolisis}

\section{a. Pengamatan Lisis Bekuan}

Setiap $1000 \mu \mathrm{l}$ darah dipindah ke tiap-tiap tabung tube yang telah ditimbang terlebih dahulu. Tabung tube yang berisi darah diinkubasi pada suhu 370C selama 30 menit setelah terbentuk bekuan darah secara langsung serum telah dihilangkan tanpa merusak bekuan, dan masing-masing tabung yang berisi bekuan darah ditimbang beratnya untuk menghitung berat bekuan darah (Arifuzzaman et al., 2011). Setelah proses inkubasi, darah yang lisis dibersihkan dengan membalikkan tabung tube sehingga darah yang lisisturun dan hanya tersisa bekuan darah pada tabung tube. Tabung tube ditimbang kembali setelah semua darah yang lisis tidak tertimbang pada bekuan darah untuk mengamati perbedaan berat bekuan darah sebelum dan sesudah perlakuan. Perubahan berat bekuan darah tersebut dibandingkan sebelum dan sesudah perlakuan untuk mengetahui persentase lisis bekuan darah. Penurunan berat bekuan darah antara kelompok uji dengan kelompok kontrol dihitung persentase lisis bekuan darahnya, 


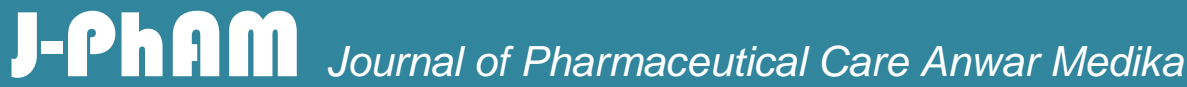

Artikel Penelitian

\section{HASIL PENELITIAN}

\section{Karateristik Tanaman Uji}

Tanaman yang digunakan pada penelitian ini yaitu lengkuas merah yang didapatkan dari Balai Materia Mediaka Batu Malang, Jawa Timur. Berdasarkan hasil determinasi yang dilakukan oleh Balai Materia Medika diketahui bahwa Jenis Lengkuas Merah yang digunakan sebagai bahan penelitian ini adalah spesies Alpinia purpurata (Velli) K.schum. Bagian tanaman lengkuas merah yang digunakan pada penelitian ini adalah bagian rimpang yang diperoleh dalam bentuk serbuk simplisia. Berdasarkan determinasi juga disebutkan bahwa rimpang lengkuas merah mengandung senyawa saponin, alkaloid, tanin, flavonoid, serta minyak atsiri.

\section{Karateristik Subjek Penelitian}

Sampel darah diperoleh dari subjek wanita dengan usia 20-25 tahun yang memiliki tekanan darah normal berkisar antara 90/60 mmHg - 120/80 mmHg (Blood Pressure Association UK), gula darah normal yaitu GDA <200 mg/dl (Fitria, 2018), dan kadar kolestrol yang normal $\leq 150 \mathrm{mg} / \mathrm{dl}$ (Sisiawati, 2018).

\section{Hasil Pemisahan Alkaloid Total Rimpang Lengkuas Merah}

Dari 750 gram serbuk simplisia rimpang lengkuas merah diperoleh hasil ekstrak etanol sejumlah 22,89 gram dengan nilai rendemen 3,8\%. Berdasarkan hasil uji fitokimia didapatkan bahwa hasil ekstraksi maserasi tersebut terdapat alkaloid. Selanjutnya, dari 22,89 gram dilakukan pemisahakan 10 gram ekstrak rimpang lengkuas merah, didapatkan 420 mg ekstrak alkaloid total rimpang lengkuas merah dengan kadar sebesar $4,2 \%$. 


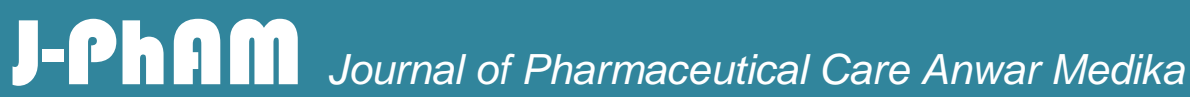

Artikel Penelitian

Hasil Analisis Uji Aktivitas Fibrinolisis Hasil Uji Normalitas Data Persentase (\%)

Fibrinolisis

Hasil uji normalitas menggunakan Analisis Shapiro Wilk (SPSS 20) bahwa distribusi data tidak normal.

Hubungan Antar Konsentrasi Alkaloid Total Rimpang Lengkuas Merah 0,1, 0,5 dan $1 \mathrm{mg} / \mathrm{ml}$ Terhadap \% Fibrinolisis

Berdasarkan hasil Kolerasi Pearson diketahui bahwa nilai koefisien kolerasi rhitung $=0,379<$ rtabel (rtabel 0,900) dengan taraf signifikansi $\mathrm{p}=0,5 \quad(\mathrm{p}>0,05)$ sehinggaHa. 2 ditolak artinya tidak ada korelasi yang signifikan antar konsentrasi 0,1, 0,5 dan $1 \mathrm{mg} / \mathrm{ml}$ terhadap persentase fibrinolisis. Hal ini menunjukkan bahwa penambahan konsentrasi pada rentang $0,1 \mathrm{mg} / \mathrm{ml}$ sampai dengan $0,5 \mathrm{mg} / \mathrm{ml}$ maupun $0,5 \mathrm{mg} / \mathrm{ml} \mathrm{sampai}$ $1 \mathrm{mg} / \mathrm{ml}$ tidak berpengaruh signifikan terhadap peningkatan persentase fibrinolisis yang artinya persentase fibrinolisis dengan pemberian $0,1 \mathrm{mg} / \mathrm{ml}, 0,5 \mathrm{mg} / \mathrm{ml} \mathrm{dan} 1 \mathrm{mg} / \mathrm{ml}$ bernilai hampir sama.

Berdasarkan hasil uji kolerasi diperoleh bahwa pola hubungan yang tergambarkan antar konsentrasi bernilai positif yang ditunjukkan dari nilai r yang positif. Hubungan positif yang artinya semakin tinggi konsentrasi alkaloid semakin besar persen fibrinolisis. Adapun kekuatan hubungan antar konsentrasi terhadap peningkatan persentase fibrinolisis dikategorikan cukup kuat yang ditunjukkan dari nilai $r$ (koefisien korelasi $=<0,379)$ meskipun hubungannya tidak signifikan karena rhitung $<$ rtabel dan nilai $\mathrm{p}=0,5(\mathrm{p}>0,05)$.

\section{PEMBAHASAN}

Tanaman lengkuas merah yang diperoleh dari Materia Medika batu Malang merupakan Jenis Alpinia Purpurata (Viellin) k.Schum yang didapatkan dalam bentuk serbuk simplisia rimpang. Jenis tanaman ini merupakan tumbuhan yang rumpun tingginya bisa mencapai 7-17 cm (Dalimartha, 2009) yang dapat tumbuh didaerah tropis, mendapatkan sinar matahari yang banyak, tanah sedikit lembab. 


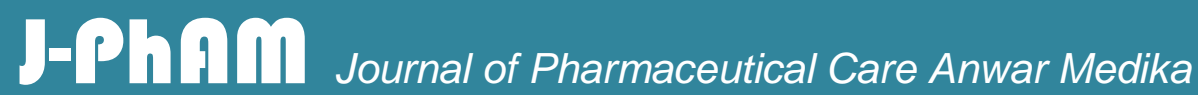

\section{Artikel Penelitian}

Kandungan kimia dari rimpang lengkuas merah berdasarkan determinasi dari Materia Medika Batu Malang yaitu daun dan akarnya mengandung alkaloid, flavonoid, fenol dan terpenoid, lengkuas merah yang paling baik digunkan adalah rimpang dan buahnya pada kedaaan segar atau telah dikeringkan yang mempunyai efek farmakologinya seperti menetralkan racun, menghilangkan rasa sakit dan pembersihan darah.

Tanaman lengkuas merah yang telah diekstraksi diproleh alkaloid total yang di ujikan sebagai aktivitas fibrinolisis. Parameter yang diamati nilai persen (\%) fibrinolisis berdasarkan nilai Clot lysis (CL), nilai persen fibrinolisis diamati saat bekuan darah telah lisis saat diberi perlakuan dengan alkaloid ekstrak rimpang lengkuas merah. Penelitian ini terdiri dari 5 wanita untuk 5 kali ulangan dengan berusia 20-25 tahun dalam kedaan sehat, kondisi kadar gula, kolestrol dan tekanan darah normal. Darah diambil $5 \mathrm{ml}$ persubjek untuk 5 perlakuan, perlakuan menggunakan etanol dengan darah sebagai kontrol negatif, perlakuan nattokinase dengan darah sebagai kontrol positif karena nattokinase memiliki aktivitas fibrinolisis yang besar mampu menginaktifkan PAI-1, pelakuan diberi konsentrasi $0,1 \mathrm{mg} / \mathrm{ml}, 0,5 \mathrm{mg} / \mathrm{l}$ dan $1 \mathrm{mg} / \mathrm{ml}$.

Hasil ekstrak etanol rimpang lengkuas merah dilakukan pemisahan alkaloid, alkaloid berdasarkan prinsip ekstraksi asam basa umumnya alkaloid di dalam tumbuhan terikat dengan asam organik membentuk garam. Garam alkaloid ini yang kemudian akan diekstraksi dengan pelarut yang sesuai, penelitian ini menggunakan etanol untuk proses isolasi yang diharapkan garam alkaloid dapat diekstraksi dalam pelarut etanol karena etanol merupakan pelarut polar yang mudah melarutkan senyawa garam. Setelah dilakukan percobaan uji alkaloid pada tanaman rimpang lengkuas merah menunjukkan hasil positif pada alkaloid karena pada sampel tanaman pada saat ditambahkan Uji Mayyer terdapat endapan, saat dilakukan Uji Dragendorff terbentuk endapan merah dan pada Uji Wagner terbentuk endapan coklat. Setelah didapatkan ekstrak etanol rimpang lengkuas merah dilakukan penapisan uji fitokimia untuk melihat ada tidaknya senyawa alkaloid dalam ekstrak rimpang lengkuas merah bahwa bernilai positif alkaloid dan bernilai negatif pada saponin, tannin dan flavonoid. 


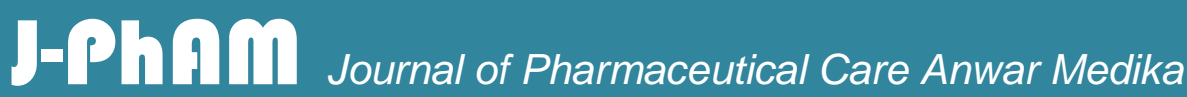

Artikel Penelitian

Selanjutnya dilakukan perhitungan rendemen ekstrak rimpang lengkuas merah sebanyak $3,8 \%$.

\section{KESIMPULAN DAN SARAN}

Berdasarkan hasil yang didapatkan, maka dapat disimpulkan bahwa hasil identifikasi yang didapatkan dari balai Materia Medika Batu Malang, sebagai bahan penelitian diperoleh sebuk rimpang lengkuas merah dengan jenis spesies Alpinia purpurata (Viellin) K.schum dan ekstrak alkaloid yang didapatkan sebanyak 22,89 gram. Hasil uji beda dengan Kruskal Wallis menunjukkan adanya perbedaan persenfibrinolisis pada kelompok perlakakuan darah yang ditambahkan konsentrasi 0,1, 0,5, $1 \mathrm{mg} / \mathrm{ml}$ ekstrak alkaloid tital rimpang lengkuas merah dengan kontrol negatif (darah +etanol) dan kontrol positif (darah+Nattokinase). Hasil uji pengaruh regresi linier menunjukkan bahwa rimpang lengkuas merah memiliki pengaruh yang signifikan terhadap persen fibrinolisis dengan aktivitas optimum pada konsentrasi $1 \mathrm{mg} / \mathrm{ml}$. Hasil uji kolerasi pearson menunjukkan bahwa tiap konsentrasi memiliki aktivitas yang hampir sama namun hubungannya lemah yaitu semakin besar konsentrasi semakin besar bekuan lisis. Pada penelitian selanjutnya sebaiknya dilakukan lebih lanjut untuk mengeksplorasi jalur fibrinolisis terhadap konsentrasi pada alkaloid rimpang lengkuas merah dan penelitian lebih lanjut tantang uji aktivitas fibrinolisis dengan ekstrak alkaloid total rimpang lengkuas merah secara in vivo.

\section{UCAPAN TERIMA KASIH}

Peneliti mengucapkan terima kasih kepada semua pihak yang terkait dengan penelitian ini. Ucapan terimakasih juga kami sampaikan kepada pihak STIKES Rumah Sakit Anwar Medika Sidoarjo yang memberikan fasilitas untuk menunjang pelaksanaan penelitian ini. 


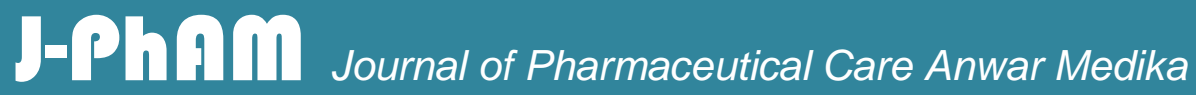

Artikel Penelitian

\section{DAFTAR PUSTAKA}

1. Agung Anak G.B. Peran system fibrinolisis pada berbagai proses fisiologi dan patologis. Devisi Endokrinogi dan mtabolisme bagian ilmu penyakit dalam. FK UNUD/RS Sanglah Denpasar.

2. Arbind, K., manisha dan Kaur, J. 2011. Fibrinolityc Agent in reference to fungi:An overview. j. of Pharm. Sci., 411: 4225-4229

3. Azzahra, F., Lukmayani, Y., \& Sadiyah, E. R. (2015). Isolasi dan Karakterisasi Alkaloid dari Daun Sirih Merah (Piper Crocatum Ruiz \& Pav), 45-52.

4. Bakta, I. M.2007. Thrombosis dan Usia lanjut. Jurnal Penyakit Dalam. Denpasar. Devisi Hematologi dan Inkologi Medik Bagian Penyakit Dalam Fakultas Kedokteran Universitas Udayana/RS Sanglah. Vol 8: 148-160.

5. Brunton, L. L. 2006. The Pharmacological Basis Therapeutics.11th Edition. New York: Mc Graww Hill.

6. Binder R, Christ G, Florian, Grubic N, Hufnagl P, Krebs M, et al. Plasminogen Activator Inhibitor 1: Physiological and Pathophysiological Roles. News Physiol Sci 2002; 17: 56-61

7. Chang, C. T., Fan, M. H., Kuo, F. C., \& Sung, H. Y. 2000. Potent Fibrinolytic Enzyme from a Mutant of Bacillus subtilis IMR-NKI. J. Agric. food Chem., 48: 3210-3216.

8. Dalimartha. 2009. Atlas Tumbuhan JIlid 6. Pustaka Bunda: Jakarta. Ghoshal, Kakali, dan Bhattacharyya M. 2014. Overview of Platelet Physiology: Its Hemostatic and Nonhemostatic Role. Disease Pathogenesis. London: Hindawi Publishing Corporation. Volume 2014. Article ID 781857: 1-17.

9. Siregar, C.J.P. dan S. Wikarsa. 2010. Teknologi Farmasi Sediaan Tablet: Dasardasar Praktis. Jakarta: EGC.

10. Rojas, S., S. Guisao, dan V. Ruge. 2012. Functional Assessment of Four Type of Disintegrants and Their Effecton the Spironolactone release Properties. AAPS PharmSciTech. 13(4) : $1054-1062$ 


\section{Artikel Penelitian}

11. Rowe, R.C., P.J. Sheskey, dan P.J. Weller. 2003. Handbook of Pharmaceutical Exipients. Edisi IV. London: Publisher Science and Practice Royal Pharmaceutical Society of Great Britain.

12. Cartensen, J.T. 1977. Pharmaceuticl of Solid Dosage Forms. New York: A Wiley Interscience Publication John Wiley and Son.

13. Departemen Kesehatan Republik Indonesia. 1979. Farmakope Indonesia (Edisi III). Jakarta: Direktorat Jenderal

14. Banker, G.S., and N.R. Anderson. 1986. Tablets. Philadephia: Lea and Febier.

15. Cartensen, J.T. 1980. Tableting and Compression, in Solid Pharmaceutical : Mechanical and properties \& Rate Phenomenom. USA: Academic Press, Inc Ltd.

16. Gunsel, W.C., and J.L. Kanig. 1976. Tablet in Lachman, L., Lieberman, H.A., \& Kanig, J.L., (Editors) The Teory And Practice Of Industrial Pharmacy Ed $2^{\text {nd }}$. Philadelpia : Lea and Febiger.

17. Katzung, B.G., S.B. Masters, dan A.J. Trevor. 2014. Pharmacology Examination \& Board Review. New York: Mc- Graw Hill. 